\title{
Diversity in Early Childhood Education Through Parents' Perceptions
}

\author{
1,2Department of Early \\ Childhood Education, \\ University of Thessaly, Greece \\ corresponding email: \\ magos@uth.gr
}

| Kostas Magos ${ }^{1, *} \mid$ Konstantina Kalopita² |

\begin{abstract}
The management of diversity in preschool framework are today one of the main goals of early childhood education. In addition to the school environment, the family also plays a key role in promoting, or not, the acceptance of diversity. The positions and attitudes of parents employed by their children affect, directly or indirectly, the pedagogical practices that teachers usually develop. The purpose of this research was to investigate the perceptions of parents with preschool children about issues of managing diversity in the context of preschool education. Also, this research aimed to determine whether and to what extent the family environment makes efforts to raise young children's awareness across cultural diversity. The research emerged that about half of the parents, although they initially invoked a neutral attitude towards the cultural diversity encountered in the kindergarten classes, in their deepest views seem to accept the otherness only if it does not make its appearance clearly visible in the classroom.

KEYWORDS

Early childhood education; kindergarten; diversity; parents perceptions
\end{abstract}

\section{INTRODUCTION}

Ethnocultural diversity is internationally considered to be a key feature of school classes of all levels. The different cultural, linguistic, social, religious elements presented in contemporary multicultural classes are regarded as an exchange of cultures and an opportunity to develop intercultural communication and interaction (Stier, Tryggvason, Sandström, \& Sandberg, 2012). This is the main purpose of intercultural education, which is now a dominant educational dimension in many countries. According to Rolanda-Ricci (1997), the main purpose of intercultural education is to reduce stereotypes and prejudices towards the different 'other', specifically, to break the cultural barriers and promote respect for any type of otherness. The main pursuit of intercultural education is to cultivate the skill of empathy, a skill that should be cultivated from pre-school age (Levin, 2003).

The issues relating to the management of diversity in preschool framework are today one of the main goals of early childhood education (Murray et al., 2015). With the implementation of appropriate practices, young children fit into a context that embraces and welcomes the cultural diversity (Ogletree \& Larke, 2010). According to Alves (2016) kindergarten students need to understand and build feelings of empathy for the different, since the experiences they form from this age have a pivotal and long-term influence on their subsequent development and education (Sakellariou \& Rentzou, 2011).

In addition to the school environment, the family also plays a key role in promoting, or not, the acceptance of diversity. The family environment is characterised as the first 
educational framework of a child and his only role model until the child enters in pre-school education.

\section{LITERATURE REVIEW}

The positions and attitudes of parents employed by their children subsequently affect, directly or indirectly, the pedagogical practices that teachers attempt to develop (Miklikowska, 2016). Parents' attitudes towards otherness show differences that seem to be correlated to their social and educational background (Tafa \& Manolitsis, 2010). Vanderbroek (1999) refers to 'parental ethnotheories', which are shaped by the cultural background of the parents and which differ between families. Parental theories are shaped by the dominant views of parents, on the approach to issues concerning both their own and 'other' cultures. Among these issues, those which are related to the management of otherness occupy an important place and are, therefore, related to the attitudes that parents themselves often advise their children to hold towards their classmates of different ethnic or cultural backgrounds.

According to Miklikowska, Bohman \& Titzmann (2019) many of the parents seem to maintain stereotypical perceptions and attitudes about diversity which are gradually transferred to other family members and especially to younger children who, due to the age, have not yet developed critical thinking. The ambient atmosphere regarding perceptions and attitudes towards otherness, affects children, enhancing or hindering the development of their empathy (Miklikowska, 2017). Some parents who usually maintain a negative attitude towards the presence of diversity in school, but also in general, they consider their presence as a threat to the dominant culture and hence they believe that their children should prioritise the dominant culture higher than other cultures (Nieto, 2004; Banks, 2016). It is palpable that parents who convey views like those mentioned above, accept the theory of cultural deficit, according to which the dominant culture is ranked as superior, while those who do not belong to it, are considered culturally deficient.

According to Dhont \& Van Hiel (2012), the influence of parents' negative perceptions of otherness plays a determining role in the perceptions that their children will form, unless the latter maintain personal friendships with people who represent a form of otherness. Personal acquaintance and interaction with the 'other', paves the way for intercultural communication and exchange which may lead to the overcoming of previous stereotypes about diversity.

\section{RESEARCH METHOD}

The purpose of this research was to investigate parents' perceptions regarding the management of diversity in early childhood education. Specifically, the research seek to examine the perceptions of parents with preschool children about the issues of managing diversity in the context of preschool education. Simultaneously, this research aimed to determine whether and to what extent the family environment makes efforts to raise young children's awareness across the cultural 'Other'.

The research involved 15 parents (nine mothers and six fathers), both men and women, whose children were enrolled in preschool education in the school year 2018-2019. Of the total number of parents, 10 are between 30 and 40 years old, 4 parents are in the age group of 40-50 years and 1 parent is in the age group of 18-30 years. The 11 are graduates of higher education, 3 graduates of senior high school and 1 graduate of elementary or junior high school. The majority of parents are of Greek descent with the exception of one father who is of Russian descent.

As appropriate methodological option for collecting data was chosen a qualitative approach and in particular the technique of semi-structured interview. Semi-structured 
interview is used in a variety of qualitative research as an instrument of flexibility and customization of the questions in each evolving interview in person. Through the semistructured interview, the deeper perceptions of the participants can be approached, as they emerge through the appropriate questions of the interview guide, but also the experience of the researcher. In the present study, the interviews were recorded, with the permission of the participants. This was followed by a transcript, then a categorization and processing of the findings by the method of qualitative content analysis.

This method highlighted four thematic categories. The first concerns the views of parents regarding the coexistence and co-teaching of children with different national, linguistic and religious backgrounds in early childhood education. The second category focuses on parents' views on kindergarten school practices related to diversity management. The third category deals with parents' views on their children's relationships with classmates who do not belong to the dominant ethnocultural group. Finally, the fourth category contains findings concerning the references which are made within the family about diversity, mainly between peoples and religions. Then some indicative views of parents are presented and discussed for each of the above categories. The interviews were numbered based on the order in which they were conducted (I 1 to I 15).

\section{RESULTS AND DISSCUSSION}

\section{Results}

\section{The parents' beliefs about diversity in Early Childhood Education}

The 6 out of 15 parents ( $40 \%$ of the sample) reported that they are neutral about the existence of different multicultural elements in preschool education. However, despite declaring a neutral stance, they argued as negative and possible that a dominant culture might be threatened by multicultural elements in pre-school education, which may conceal feelings of fear, threat and anxiety about the 'Other'.

"I believe that there is no specific issue [...] That is, it is not negative [...] as long as they... go with us, no problem is caused. To be integrated into our society." (I 10)

"In this case I do not bother but I would not like the presence of foreign children in school to be the majority. It is good to have get to know different cultures, but I am afraid that more than enough may be negative, because it can affect our culture and our customs." (I 12)

"Teaching many different religions is not feasible, in my opinion. I also believe that in this way the traditions of our religion are influenced and perhaps are being altered." (I 7)

"I do not find it positive. Tradition will be altered, and the little ones will hardly be pious citizens." (I 6)

The previous viewpoints obviously express an assimilative perception towards otherness, a perception which is contrary to the aims and principles of intercultural education.

Contrary to the above view, $7 / 15$ (46\% of the sample) parents claim that the coexistence of different cultures brings positive elements to young children. Some of them claim that through the different stimuli that their children receive, their horizons are widened, and their experiences are enriched. The following excerpts are indicative:

"It is a positive fact [the coexistence of different children] because it enriches the children's performances." (I 4) 
"I think it is a positive fact that there are different cultural elements in the kindergarten because it is representative of our multicultural society, it teaches children from a very young age the coexistence and interaction with other civilizations and cultures. " (I 1 )

"It is good for children to be aware of the fact that there are more religions and other children believe in another god but there should be mutual respect and acceptance of each other." (I 5)

Opinions such as these, highlight parents who seem already aware and open towards diversity. But even among them, there seems to be concern about whether the coexistence of indigenous and non-native students hinders the progress of the former. Characteristic is the following excerpt from I5:

"Let's say, a child who does not know the language or who doesn't speak Greek fluently, will need some help to continue and not hinder learning. Eh.... no one has a problem as long as it does not cause a problem for others. All children should learn." (I 5)

Such a view ultimately seems to express an ambivalence towards the acceptance of otherness, that is, not a total acceptance, but a conditional acceptance. The 'Other' is accepted only as long as it at least does not 'disturb' the cognitive development of the dominant group just as the parents understand the cognitive development and is usually focused on covering the current curriculum. Therefore, the dominant culture is considered as the most important, to which others are obliged to compromise.

Respectively, the preference of a homogeneously religious order is also proposed by I3 as it typically says:

"Um, maybe I would prefer all the children to be of the same religion in order to avoid creating tensions but if they wouldn't be, I wish they would not influence or tease one another."

It is palpable that the mother means that she would prefer that there were no religiously different students in the kindergarten class, that her child attends, because she believes that this creates tensions. The preference of the homogeneous class, in this excerpt too, seems to conceal an assimilative approach, where the desire for the dominant religious approach is indirectly expressed. She also argues that religious diversity even in kindergarten can be an element of tension and conflict, despite a fruitful experience of introducing young children to other religions.

Religious diversity in Kindergarten seems to 'scare' and concern parents more than the dominant one. Even parents who declare themselves to be open to the coexistence of students of Greek and non-Greek origin, express views in favor of school prayer, which in their opinion should reflect the religion of the dominant group, otherwise they fear that a 'religious degenenaration' may be caused. Typical are the following excerpts:

"I am glad that religious prayer is being held because we want our children to believe in Christ as it is our religion and... no matter how you do it, we should not forget it or alienate it." (I 5)

"They say the orthodox Christian prayer. $\Omega$ I totally agree... They have to do it and I like that they follow it." (I 6)

\section{Kindergarten (intercultural) practices (for diversity) through parents' eyes}

The second category presents the views of parents about the activities which are carried out with regard to diversity in Kindergarten, as well as the corresponding educational material. 
Most parents who participated in the survey did not know if diversity-related activities had taken place $(60 \%)$, while a smaller portion had information and examples through their children (40\%). Some parents, unaware of the exact activities that teachers may carry out to raise young students' awareness of the 'Other', report that some discussions take place to answer the questions raised by children, both through their 'Other' classmates and for reasons given by fairy tales or other references.

"They have questions such as why the [foreign] child is missing from school and [the children] try to explain to each other things that they are unable to understand adequately. Kindergarten teachers answer simply and with little information about it, that they have other religious holidays and that they have a different Easter, that they do not eat pork." (I 5)

"Some special activities, no... For languages, differences of people and skin colors... Some pictures although I think all kindergarten schools do the same things. Something more specific and special no." (I 15)

"I think they do something with flags and languages and that they watch some videos with people of different physical appearance." (I 14)

Regarding the adequacy of the activities, the comments of the parents, who seem to have an opinion on what is happening in the kindergarten, indicate a desire for more frequent awareness activities on diversity.

Maybe yes, they can enrich the stimuli. To project more audiovisual material and to make more reports about diversity by giving children small information that they can understand and remember... (I 5)

A parent of the case in study found the activities insufficient. The parent considers that the main cause is the 'fear' of kindergarten's teacher about how intolerant parents may react. He said characteristically:

"In order to be adequate, a child must want to tell something that impressed him/her...They probably do what they always do, as the parents are not very tolerant. That is, [kindergarten teachers] would be severely criticized under different conditions [if they did more activities related to diversity]." (I 15)

Regarding the educational material, a significant percentage (9/15 parents) states that in the kindergarten there is material related to the diversity of peoples and cultures, which is either used by the kindergarten teachers or the children themselves have the opportunity to approach it.

"There must be a book on diversity in kindergarten, it just hasn't been read to them as far as I know but the kids have discovered it and peruse it... they look at the pictures and imagine/ make up stories." (I 1)

"It is available in kindergarten and is often used. A prime example is the use of computer for viewing short video presentation of the world for different places and people and I think about diversity in general." (I 11)

"Yes, there is. There are many reports about the different skin colours of children and their origin through photos. I think they are presented to them on children's books or some videos, the books are about other countries children of their age who live there." (I 2)

One parent reports that despite the fact that there is material about diversity, teachers do not use it regularly as they believe that some parents in the classroom do not want similar 
references because they believe they estrange young students from the dominant culture, traditions and customs.

"Yes, books on diversity. They are used very little because children are not interested eh... none of parents want specific references. They believe that this is how children move away from Greek culture." (I 7)

Contrarily to this view showing the kindergarten teachers afraid to carry out activities regarding diversity, due to possible negative reactions of parents, the following excerpt, from a parent interview, describes an approach that respects the linguistic diversity and is completely compatible with the framework of intercultural education.

I do not know exactly [what activities they do]. All I know is that in their school try either children from another country or children who speak another language as well as their parents try to speak their mother tongue. To wit, the teachers tell the children and their parents to speak their mother tongue in addition to Greek and practise both of them. Even the children who face up difficulties with Greek language, are urged by the teachers to speak regularly both of them, you should not give up your language..This at least happens in this kindergarten... (I 10)

\section{The relationship among the students of kindergarten}

The majority of the parents in the case in study, $13 / 15$ parents $(86 \%)$ of the sample, claimed that their children maintain good friendships with foreign or of different religions children and sometimes refer to them some of their conversations at home. It is often said that children try to discover other friends' cultures or language differences through discussions or questions, such as learning and using certain foreign words in their own language. Representative are the following excerpts to the posed question: 'What is your child's relationship with the children in the class who have another origin, language, religion?

"Very good. With some of these children and their parents we meet each other also out of school." (I 3)

"Very good. He/She plays and talks like with the other children, I do not know if he has understood if he is from another country as he/she and the little girl come together from the kindergarten and they have always been friends. " (I 6)

"Pretty good... She has some worries but usually asks and we solve them. He does not associate with them, but they cooperate well during activities and games."(I 14)

"I like the fact that she hangs out with everyone and decides by herself with who she socializes or not. Nationality or language or even religion does not matter." (I 15)

As it turns out, children's relationships are not limited to the kindergarten area but extend beyond it, such as in the park of the neighborhood. Overall, a good relationship is reported between toddlers, which is not defined by religion, ethnicity or language.

\section{Approaching diversity within the family}

The 46\% (7/15) of the parents felt that there are no frequent references or discussions about diversity, only on the occasion of some news they heard or on the occasion of something they discussed at school, which is usually of minor importance. In contrast, 53\% (8/15) parents who stated that they held discussions and reports on diversity between peoples and religions argued that, it happens regularly, while they talk about the content of the books and school material at home, or the discussions take place through experiential circumstances, 
such as an excursion to the geographical area of Thrace where live a Muslim minority population

"We had discussed it (diversity). His godmother lives in Thrace and we went to see her this year. There we met women with headscarves and explained to them why they wear them and some facts about their religion. At first, they looked at each other in question but then they got used to it and understood and showed empathy at some point." (I 9)

"We talk about the difference between cultures, usually from children plays or fairy tales. Concerning the languages, we usually refer usually to English. He knows that there are many religions, but we do not have much discussion." (I 7)

"Of course... We have discussed and explained the current situation with the refugees. They also know the reason why everyone speaks English and that there are also other important cultures, we travel a lot and this year we took them on their first trip abroad, in which they seemed excited." (I 15)

To the question "Do you carry out activities -beyond the discussion- at home that are related to different cultures, languages or religions?" The majority of parents $(11 / 15)$ responded negatively.

"No no... there is no time for such a thing!" (I9)

"No, this does not happen and I do not find the reason for such activities. " (I 13) The smallest portion of parents (4/15), who stated that they carry out activities for the diversity of peoples and religions, linked the event with the learning of the English language, an element that obviously has little to do with awareness of different cultures, since the English is an internationally dominant language.

"We have an English book with songs and language exercises for learning English. We do not do anything else." (I 1)

"We watch English language programs on the internet and listen to songs with English lyrics which help them learn and get in touch with something different." (I5)

A parent of non-Greek origin states that they carry out activities related to their origin.

"My parents teach the children Russian which is also our mother tongue as we are

Russian-speakers and they definitely practise language games. "(I 10)

Finally, another parent claims that they make references to religious or ethnic diversity in order to stimulate children's critical thinking:

"We do not take specific activities, however, there are frequent references to the difference of religion and nationality, and we show them books and videos that happen to interest us and thus stimulate their thinking about the different." (I 11)

In similar context shape the responses of parents to the question "Is there an educational material at home, which refers to the diversity of people?" The 11/15 parents answered that there is nothing similar and 4/15 parents stated that they do have material about diversity. The latter said characteristically:

"There are some travel guides, English books, books related to the flags of other countries. More specifically... mainly literary books written in English. (I 5)

We have various books that refer to different nations, without being aimed at 'teaching diversity'. These can be 'geography' books, natural or just children's stories with characters from different parts of the world." (I 4) 
Unlike most parents, children seem to make references on other peoples' cultural elements in the family environment. 11 out of 15 parents (73\%) said that children ask and discuss various issues related to diversity, seeking explanations and answers to their questions.

"They narrate possible cultural differences with enthusiasm or wonder. It depends. Mostly they do not understand the way that they speak two languages at the same time or about different religious elements. He/She once mentioned a Chinese game that a child from China had taught them and that was played by the whole class." (I 12)

"They report some questions about the differences between religions and cultures. Like what happens at their Christmas. How they celebrate in Albania their national anniversary. At times I know the answer, sometimes technology helps and other times I tell her that she can ask her classmate about more information." (I 14)

The last excerpt highlights the pedagogically correct attitude of the mother towards the questions of her little daughter. She listens to the questions and discusses them with her, trying to find the information she needs. Using the internet seems to be a good solution, as parents may not know the answers to their children's questions with cultural content. Finally, the mother's urge to ask her foreign classmate is also correct, as it promotes direct intercultural communication and cultural exchange between young children.

\section{Discussion}

As the present research emerged, about half of the parents who participated in the research, although they initially invoke a neutral attitude towards the cultural diversity encountered in the kindergarten classes, in their deepest views seem to be in favor of an assimilative approach, to wit an approach that accepts the otherness only if it does not make its appearance visible in the classroom. Assimilative perceptions of heterogeneity management have been prevalent internationally in immigrant host countries for long periods of time, while still appearing frequently in both educational and wider social space (Nieto, 2004). Therefore, the initially neutral attitude of parents is rather a way of avoiding stating their points of view, perhaps knowing that such views may contradict the views of other parents and/or researchers. The remaining approximately half of the parents state that they consider cultural coexistence in the context of preschool education as a positive event, as it helps them to broaden the horizons of children and enrich their experiences. But even this group of parents often seems to show ambivalence as it sets conditions for the co-education of the children of the dominant group with the 'other' children. As main arguments concerned the possible delay of the native students in their language development, as well as their possible negative influence on the dominant religious beliefs. The fear of the members of the dominant group, to wit those of Greek origin and Orthodox Christianity, for possible national and religious alienation due to the coexistence of the indigenous population with members of other ethnic and religious groups has also emerged in other researches (Magos, 2006).

Religion seems to be an important parameter for the Greek family and the school is called upon to respond to the cultivation of faith in the dominant dogma. Although the parents state that the acquaintance of the children with other religions in the context of the kindergarten is a positive element, some of them in the continuation of the discussion express their fear towards the religious alienation. Therefore, the ambivalence of parents towards the management of diversity in Kindergarten can be seen here as well, a situation that could be justified on the one hand by the significant influence they continue to have dominant monocultural and assimilative perceptions and on the other hand by their lack of information about values and the role of intercultural education.

Regarding the teaching practices 
used in the Kindergarten where their children attend, most parents $(60 \%)$ stated ignorance, while the rest made general references to relevant discussions that can take place in the classroom, to questions that children have and are answered by teachers, as well as in teachers' reports on the diversity of languages, religions, etc. Of interest is a parent's argument for the limited number of activities that teachers carry out and which focuses on the fear of reactions from parents. According to Androussou, Dragonas and Magos (1998), parents of the dominant group often react to the initiatives of kindergarten teachers to implement intercultural actions in practice, which highlights the need for intercultural awareness of parents as well.Regarding the educational material used in the kindergarten, the parents refer mainly to books and fairy tales. Fairy tales and children's books, with intercultural content, are a suitable source of intercultural awareness of young children, as they can act as 'mirrors and windows' (Bishop, 1990), to wit as a means of acquaintance with other cultures, but also for a deeper acquaintance with the dominant culture.

The majority of parents claim that there is a good relationship between their children and children of different backgrounds, languages or religions. Moreover, the fact that some of them promote intercultural communication outside of school highlights that the reunion of children is not only due to the compulsory joint study, but also due to the desire of parents to maintain communication. It seems that the concerns which were expressed in a previous question by many parents about the co-education of natives and non-native students do not affect the relationships between children, who need to make friends regardless of the cultural context of the family they belong to (Levin, 2003). Friendships between children that can be formed both at school and outside of it, compose an appropriate environment for the development of strong bonds of intercultural interaction.

Regarding whether and how the parents in the family are involved in the intercultural awareness of their children, about half of the parents (7/15) answered that they do not have relevant discussions with their children, meaning on their own initiative, while the other half (8/15) answered positively, saying that there are discussions and reports on issues of otherness for various reasons, to wit some material that exist at home or through an excursion that took place in another place. But beyond the discussions, the majority of parents responded negatively to the mobilization of children's intercultural thinking through other activities. However, some parents who responded positively linked the activities to learning and practising English, a process that is hardly linked to diversity management issues from the perspective of intercultural education. The answers for the existence of appropriate intercultural awareness educational material at home were similar. The small group of parents who answered in the affirmative appertained to some relevant children's books, videos or travel brochures. Given that the researchers did not have access to the material themselves, it was not possible to assess its quality, but as several materials fall into the trap of folklorization (Lee, Menkart and Okazawa-Rey, 2000), where the approach of the 'Other' is done in a non-objective way. The travel leaflets which were referred to by one of the parents are a typical case of such material.

According to the majority of parents the children themselves often bring home questions regarding diversity issues. Coexistence with classmates of a different ethno-cultural origin and/or relevant references from teachers motivate children to question and seek answers within the family. This aspect is particularly interesting because it shows that the children themselves often take the initiative to develop discussions on intercultural issues at home, even if the parents themselves hold an indifferent attitude towards such issues. The same element also highlights the importance of personal acquaintance and communication between students of the dominant cultural group and those who do not belong to it. 


\section{CONCLUSION}

As the theory and practice of intercultural education argues, interpersonal relationships can be the appropriate framework for promoting intercultural exchange and developing empathy. Family and school are the two key factors in ensuring healthy interpersonal relationships among all children, regardless of their national, religious, linguistic or other dimension of identity. Given the importance of preschool age in shaping children's perceptions and attitudes towards otherness, the role of both parents and teachers is crucial. The present research emerged that a significant percentage of the parents who participated in the research show ambivalence towards the management of diversity. Therefore, the need for intercultural awareness of parents to move from the stage of ambivalence to a stage of acceptance of otherness and the development of intercultural communication and exchange is urgently highlighted.

The conclusion illustrates the problem that has been formulated. The conclusion is not repetitive, but rather on the summary of the findings of the problems. Sometimes, the author also points out any limitations, and offer suggestions for future research.

\section{REFERENCES}

Alves, I. M. E. (2016). Teaching multiculturalism in a preschool classroom. Doctoral dissertation. Retrieved from: http://comum.rcaap.pt/handle/10400.26/19165

Androussou, A., Dragonas, T., Magos, K. (1998). Parents and the community: The missing links in the Greek school. In P. Gibbon, S. Scott (Eds), Parents as partners in education (pp.13-19). London: Intercultural Education Partnership.

Banks, J. A. (2016). Cultural Diversity and Education: foundations, curriculum and teaching (6th ed.). New York: Routledge, Taylor and Francis.

Bishop, R. S. (1990). Mirrors, windows, and sliding glass doors. Perspectives, 6 (3) ix-xi.

Dhont, K., \& Van Hiel, A. (2012). Intergroup contact buffers against the intergenerational transmission of authoritarianism and racial prejudice. Journal of Research in Personality, 46, 231-234.

Lee, E., Menkart, D. and Okazawa-Rey, M. (2000). Beyond Heroes and Holidays, Washington DC: Network of Educators on the Americas

Levin, D. (2003). Teaching Young Children in Violent Times. Washington DC: National Association for the Education of the Young Children

Magos, K. (2006). Teachers from the majority population - Pupils from the minority: Results of a research in the field of Greek minority education. European Journal of Teacher Education, 29 (3), 357 - 370.

Miklikowska, M. (2016). Like parent, like child? Development of prejudice and tolerance towards immigrants. British Journal of Psychology, 107, 95-116.

Miklikowska, M. (2017). Development of anti-immigrant attitudes in adolescence: The role of parents, peers, intergroup friendships, and empathy. British Journal of Psychology, 108, 626-648.

Miklikowska, M., Bohman, A., \& Titzmann, P. F. (2019). Driven by context? The interrelated effects of parents, peers, classrooms on development of prejudice among Swedish majority adolescents. Developmental psychology, 55 (11), 2451-2463.

Nieto, S. (2004). Affirming diversity (4th edition). New York: Pearson

Ogletree, Q., \& Larke, P. J. (2010). Implementing multicultural practices in early childhood education. National Forum of Multicultural Issues, 7, (1), 1-9. 
Rollandi-Ricci, M. (1996). Training Teachers for Intercultural Education. The Work of the Council of Europe. In T T. Dragonas et al. (Eds), Beyond One's Own Backyard: Intercultural Teacher Education in Europe, Athens: Nissos, 57-68.

Sakellariou, M., \& Rentzou, K. (2011a). Cypriot pre-service kindergarten teachers' beliefs about and practices of developmentally appropriate practices in early childhood education, Early Child Development and Care, 181, (10), 1381-1396.

Tafa, E. \& Manolitsis, G. (2003). Attitudes of Greek parents of typically developing kindergarten children towards inclusive education, European Journal of Special Needs Education, 18, (2), 155-171.

Vanderbroek, M. (1999). De blik van der Yeti. Nederlands: Swp, Uitgeverij B.V. 